\title{
La recepción transnacional del fútbol gallego. El caso de la peña "Lionel Scaloni” del Deportivo La Coruña
}

\author{
The transnational reception of Galician football. The case of \\ Deportivo La Coruña's fans club "Lionel Scaloni"
}

\author{
María Soledad Balsas msbalsas@conicet.gov.ar \\ http://orcid.org/0000-0002-7456-6977 \\ Centro de Investigaciones Sociales; Instituto de Desarrollo Económico y Social/ Consejo \\ Nacional de Investigaciones Científicas y Técnicas (Argentina)
}

\section{Resumen}

Con este trabajo me propongo contribuir a la reflexión sobre la recepción del fútbol gallego en Buenos Aires a partir del caso de la peña "Lionel Scaloni" del Deportivo La Coruña desde la 
perspectiva de la televisión transnacional. El tipo de abordaje propuesto se basa en el análisis etnográfico, presencial y virtual. El análisis de este caso muestra los límites de utilizar al grupo étnico en los estudios sobre las audiencias de televisión trasnacionales. En cambio, se hace evidente la necesidad de recuperar una noción relacional del espacio.

Palabras clave: Recepción; televisión; fútbol, etnografía; Galicia.

\section{Abstract}

Based on the case of "Lionel Scaloni" La Coruña football club, with this work I intend to contribute to the reflection on the reception of Galician football in Buenos Aires from the perspective of transnational television. The approach is based on ethnographic research methodology, in particular face-to-face and virtual types. The analysis of this case makes evident the limits of using the ethnic group in studies on transnational television audiences. In this sense, the need to recover a relational notion of space becomes also evident.

Keywords: Reception; television; football; ethnography; Galicia.

Hace casi dos décadas, Grimson, Masotta y Varela (1999) reflexionaban sobre la recepción del fútbol en bares de la Ciudad de Buenos Aires. Asumiendo el desafío de pensar la recepción televisiva en lugares públicos, estos autores argumentaban que el fútbol constituía el ritual televisivo por excelencia fuera del hogar, ámbito privilegiado por los estudios culturales anglosajones. Entonces, el bar representaba un espacio semipresencial intermedio entre el estadio y la casa en el que las mujeres sólo participaban acompañadas de varones. Desde entonces, diversos avances se verificaron en relación a los estudios sobre el fútbol. Sin embargo, en lo que concierne a su mediatización, los análisis resultan significativamente menos prolíficos, al menos en el ámbito latinoamericano. "Se han aplicado técnicas de carácter etnográfico, realizando observaciones participantes en los estadios y sus entornos mediáticos, aunque tal vez de manera insuficiente en lo que se refiere a los análisis de recepción de estos últimos" (Villena Fiengo, 2003: 30). Este trabajo aspira a constituir una contribución en ese sentido. 
Desarrollé mi labor de investigación en bares ubicados en la Ciudad de Buenos Aires. Mi atención se centró en la recepción transnacional del fútbol, entendida como práctica cultural que involucra a un número significativo de personas, observa cierta estabilidad y permanencia en el tiempo y se encuentra mediada por al menos dos contextos nacionales (Faist, 2012; Portes, Escobar y Arana, 2009). El análisis se inscribe en el marco del Proyecto Migraciones internacionales y medios de comunicación en la Argentina. La televisión transnacional entre el estar 'aquí' y el 'allá', que realizo en el Centro de Investigaciones Sociales (CIS) del Instituto de Desarrollo Económico y Social (IDES) gracias al financiamiento otorgado por el Consejo Nacional de Investigaciones Científicas y Técnicas.

En esta ocasión, presentaré lo observado durante el trabajo con uno de los cuatro grupos que seleccioné para llevar a cabo mi proyecto de investigación. Se trata de la peña "Lionel Scaloni" del Deportivo La Coruña. Si bien la perspectiva utilizada es de inspiración etnográfica, lo que a continuación se detalla no podría ser considerado un análisis etnográfico en sentido estricto, ya que, según Guber $(2011 ; 2004)$, este requiere de la observación constante y repetida en el tiempo. Dada la falta de regularidad en la organización de los encuentros, atribuible a dificultades logísticas pero acaso también al éxito deportivo del equipo durante el período analizado, no pude obtener más que una mera fotografía acaso incompleta del problema esbozado. A las notas de campo registradas durante la transmisión del clásico gallego en el Centro Galicia de Buenos Aires el 23 de diciembre de 2017 sumé una entrevista realizada por correo electrónico a una empleada de la Corporación Radio y Televisión de Galicia (CRTVG) y el análisis etnográfico virtual realizado durante 2017.

\section{Audiencias de televisión transnacionales en sus contextos}

A pesar de la existencia de diversos canales de televisión europea de alcance internacional, llama la atención la escasez de investigaciones que problematizan la recepción de la televisión europea fuera de Europa registrada hasta el momento. La situación descripta es particularmente cierta para los canales de televisión no anglosajones. En líneas generales, en Europa la discusión académica sobre la televisión transnacional ha sido orientada en gran medida por la hipótesis de la guetización cultural y ha tendido a focalizarse en la recepción de la televisión árabe en el continente. Por ejemplo, Aksoy y Robins (2005; 2003; 2000) argumentan la necesidad de reconocer el posicionamiento estratégico de las audiencias televisivas transnacionales antes que analizarlas en relación con el país de origen o como minorías étnicas dentro de la sociedad receptora. Los autores reconocen en la recepción de la 
televisión transnacional el potencial de socavar el carácter nostálgico de la imaginación diaspórica y sus imperativos de identificación y pertenencia. Aceptan la coexistencia de formas rivales de vida que dan la oportunidad de comparar, reflexionar, criticar, comprender y combinar certezas contradictorias.

No obstante la temprana preocupación por la recepción televisiva en los países latinoamericanos, las discusiones han resultado con frecuencia más conceptuales que empíricas (Lozano y Frankenberg, 2008; Saintout y Ferrante, 2006; Grimson y Varela, 1999). En este contexto, no sorprende que los estudios empíricos de recepción de la televisión extranjera por parte de las audiencias latinoamericanas resulten casi inexistentes. Los trabajos tendientes a problematizar estas cuestiones parecen concentrarse en la situación de las y los mexicanos en Estados Unidos. Tal es el caso, verbigrazia, de Uribe Alvarado (2005; 2004a; 2004b), quien estudió la recepción de telenovelas por migrantes mexicanos en Los Ángeles, California. En contraste con los hallazgos antes citados, esta autora argumenta que el consumo televisivo constituye un espacio para reafirmar el sentido de pertenencia nacional. Sin embargo, reconoce que se trata de una experiencia mediada por el género: mientras las mujeres experimentan sentimientos que tienden a fortalecer su sentido de comunidad, para los hombres las telenovelas mexicanas no reflejan en absoluto su identidad. Más aún, muestran su preocupación por lo que consideran malas actuaciones e historias poco realistas que los hacen sentir culturalmente excluidos. En cambio, el consumo de fútbol televisado resulta clave en la (re)producción de su identidad nacional.

Con todo, el fútbol se presenta como un ámbito privilegiado para analizar estas tensiones. Según Villena Fiengo (2003), la transnacionalización e hipermediatización de la audiencia futbolística suponen alteraciones en las funciones simbólicas y sociales del fútbol. La eliminación de la mediación nacionalista en la interpretación de las imágenes así como la neutralización del lenguaje, el reemplazo de códigos ideológicos por otros más técnicos y la paulatina "no lugarización" del fútbol son, en opinión de este autor, algunos de los cambios fundamentales en las modalidades de mediación propias del espectáculo futbolístico en las que el "nosotros esencial" es suplantado por versiones supranacionales como la de "nosotros los latinos", conformando una "metasfera" pública en la que se esbozan los trazos de una nueva ciudadanía global. 


\section{Recorrido metodológico}

En el contexto del presente trabajo, adopté los principales lineamientos de la etnografía virtual. Este enfoque se presenta particularmente útil para que un/a mismo/a investigador/a compare diferentes grupos que existen en ambientes virtuales simultáneamente, tarea que de lo contrario podría realizarse sólo a través de un equipo de investigación. Se focaliza en la atención a la conectividad y a la multisituacionalidad en diferentes ambientes a partir de un tema común. Incluye desde rápidos comentarios, extensos diálogos, elaboradas discusiones hasta artículos e intervenciones (audio)visuales a través de las cuales se hace referencia a programas, géneros, redes y plataformas televisivas que estructuran sectores reconocibles de la web, constituyendo el centro de una serie de prácticas discursivas (Barra, Tarantino y Tosoni, 2011). Su implementación requiere definir los límites de la observación persiguiendo el máximo nivel de apertura y de heterogeneidad posibles.

Asumí que las redes sociales podían constituir un espacio privilegiado del comentario televisivo en línea y, en consecuencia, otro modo de estudiar las audiencias. A continuación, seleccioné páginas y grupos teniendo en cuenta: a. la cantidad de inscriptos; b. el grado de participación de los miembros; c. los intereses de los participantes; y d) el tipo de intercambios entre ellos. Me focalicé en Facebook porque identifiqué diversos espacios de interés. Tomé contacto con el administrador para solicitar su autorización o bien publiqué directamente un post presentándome y haciendo evidentes mis intereses de investigación. "Debemos, como etnógrafos, hacer lo posible por revelar a nuestros informantes la naturaleza y propósito de nuestro estudio una vez que accedamos al campo" (Márquez, 2014: 118), identificándonos, haciéndoles saber que van a ser investigados, por qué y con qué objetivos. Para presentarnos, puede ser útil incluir toda la información necesaria también en nuestro perfil en redes sociales o incluso incluir el vínculo a una página web externa que ilustren nuestros trabajos y doten nuestra credibilidad como investigador/a.

Leí los posts publicados en cada grupo siguiendo el criterio de saturación y prestando particular atención a las imágenes incluidas, así como a los comentarios y diálogos suscitados a partir de cada entrada. Compilé todos aquellos que consideré podrían resultar potencialmente significativos a los fines de mi investigación. Sobre esta base, comencé analizando aspectos relativos a la temporalidad. A continuación, atendí a la intensidad discursiva, entendida como los intercambios registrados entre los miembros que permiten establecer comparaciones con otros espacios del campo etnográfico diferenciando núcleos de interés centrales y periféricos. En particular, el dinamismo del ambiente y las características de quienes lo habitan, sus formas de interacción, su ritmo y el volumen de las intervenciones. A través de la lectura y el análisis 
sistemático de las intervenciones registradas y la selección de aquéllas más significativas fui definiendo progresivamente los "conceptos sensibilizantes", es decir, las áreas genéricas de interés que orientaron la observación. En especial, me concentré en los rasgos temáticos y offtopics, en las modalidades de fruición, incluidas las ilícitas y/o no oficiales; las formas paratextuales, las metadiscusiones sobre el funcionamiento de los espacios en línea y las derivaciones hacia otros medios.

En este contexto, se fueron gestando las primeras preguntas que guiaron la siguiente etapa de la investigación basada principalmente en la observación participante. Esta técnica supone el registro, en este caso escrito, de todo lo que ocurre en torno al/a investigador/a (Guber, 2011; 2005). En tal sentido, prevé una actitud de alerta permanente de parte del/a investigador/a que no es en absoluto neutral sino que tiene un impacto directo tanto sobre los actores como su ambiente. Además, implica cierta participación por parte del observador, entendida como la profundización en la perspectiva de los actores, ya sea a través de la aproximación física, la formulación de preguntas en un contexto de comunicación recíproca y/o la experiencia directa. Si bien la entrevista antropológica tiene en común varias características con la entrevista sociológica, una de las diferencias más importantes entre ambas atañe la no directividad, es decir, las categorías de análisis no provienen del/a investigador/a sino, en general, de los mismos actores. Antes que una escucha pasiva, el/la investigador/a busca relaciones entre las informaciones proporcionadas, elabora hipótesis y ensaya explicaciones que gradualmente le permitirán conseguir niveles más sofisticados de conocimiento.

\section{Escenas de la recepción transnacional del fútbol gallego}

El corpus virtual analizado contiene 85 entradas correspondientes a la página de la Peña Argentina del Deportivo La Coruña, que al momento del análisis contaba con 969 seguidores. Se trata de un sitio ágil que se caracteriza no sólo por su dinamismo sino también por un tratamiento gráfico visualmente ameno basado en los colores del equipo gallego. Durante el período de transmisión del campeonato español, las publicaciones se suceden con frecuencia semanal/quincenal. El nivel de interacción es medio-bajo, y se expresa, por lo general, mediante emoticones. Las entradas son publicadas sólo por los administradores y los miembros pueden participar a través de comentarios. Las intervenciones incluyen generalmente imágenes fijas: banners, capturas de pantalla (televisor, computadora, pantalla gigante), fotos de partidos, de las hinchadas, de estadios, de vestuarios, de jugadores, de equipos, escenas de las "xuntadas" e íconos que remiten tanto a la identidad futbolística como 
a la argentina: camisetas, banderas y mates. Los videos incluidos corresponden a entrevistas, conferencias de prensa y spots institucionales.

El análisis de las formas temporales muestra un predominio del build-up y del release: "ya juega el Depor"; "precalentamiento en Riazor!. Vamos depor, hoy no podemos perder"; "ya tenemos conexión con España"; "ya arrancaron"; "desde Argentina viviendo Barcelona vs Deportivo la Coruña"; "Hay GOOL EN RIAZOR. Lucas Perez de penal pone el 1 a 0 al minuto 41 del 1er tiempo". Son recurrentes las referencias a ESPN, DirecTV, Cablevisión y TyC Sports así como a tarjetaroja, iguide y streamup.com. La televisión pública aparece a través de una captura de pantalla de la grilla de programación de Cablevisión que anuncia el clásico gallego en las pantallas argentinas en el canal internacional de la Corporación de Radio y Televisión de Galicia (CRTVG). Dentro del ámbito español, LaSexta y La 1 de TVE son los únicos canales con visibilidad en el grupo.

En los posts publicados predomina el uso del castellano. Sin embargo, también se registran algunas voces en gallego. El uso del gallego es observable, por ejemplo, en las acciones de difusión para convocar a las "xuntadas". Se trata con frecuencia de adjetivos posesivos y sustantivos abstractos que ligan la identidad deportiva con la lingüística, proyectando un origen compartido: "ultima xuntada da nosa peña", "xuntada da peña Bos Aires", "o noso derbi xuntos", "por outro ano unindo máis que a paixón polo fútbol, unindo os corazóns. Benvido 2015!"

A propósito de una interesante metadiscusión sobre el funcionamiento del grupo de la peña en Facebook, se vuelve explícita la dicotomía entre un "nosotros-hinchas-del-Deportivo-en-Galicia" y un "ustedes"-que-nunca-pisaron-el-estadio-del-club en la que son reconocibles argumentos identitarios que no parecen desprovistos de la puja (política) por la definición de identidades territorialmente connotadas. La discusión fue generada a partir de la publicación de una fotografía tomada durante uno de los encuentros de la peña en la que un hincha del Celta de Vigo se "enfrenta" con una actitud visiblemente irónica a un hincha del "Depor". 


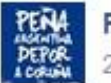

Peña Argentina del Deportivo La Coruña

22 de noviembre de 2015 -

sin caer en la demagogia,

este fue nuestro verdadero partido ganado.

Hemos vivido una tarde fantastica, junto a hinchas del Celta.

En donde no faltaron las cargadas, los gritos, el sufrimiento y demas. Pero cuando el arbitro pitó el final. Nos dimos un abrazo, brindamos, cantamos y nos quedamos a compartir juntos de la mesa. Este es O NOSO DERBI !

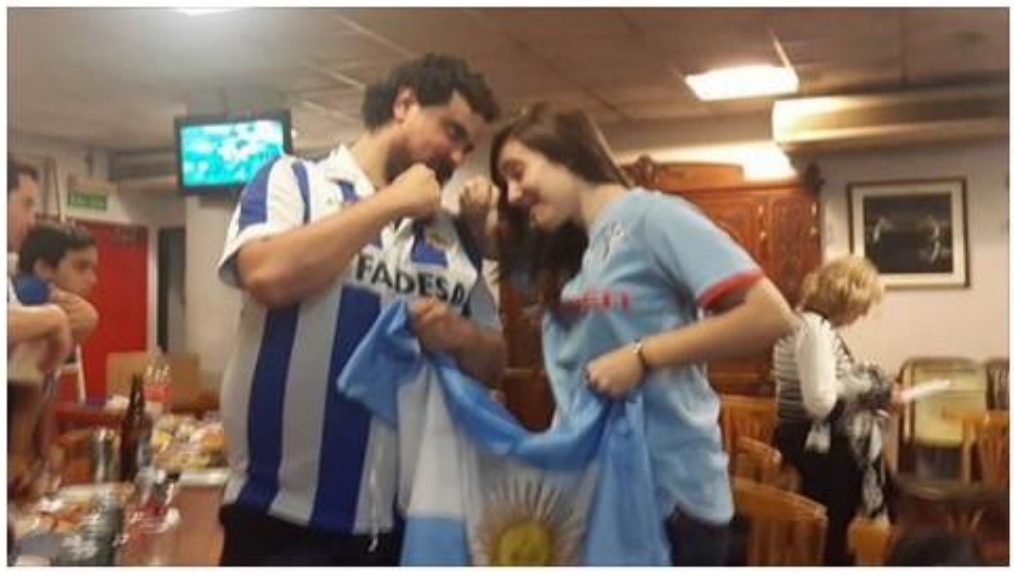

Figura 1. Rivalidad(es) futbolísticas e identitarias. Captura de pantalla [Facebook], 22 de noviembre de 2015.

La dimensión transnacional es reconocible principalmente a través de la tematización de la distancia y la diferencia horaria entre "el aquí" y "el allá", muy sentida por las y los participantes: "la transmisión de ESPN play se quedá [sic] en el entretiempo, mostrando highlights, estadísticas y una imagen fija del Madrigal. Que [sic] lindo sería que fuese así siempre. Una experiencia única que nos hace sentir como en el estadio". Si la televisión disminuye -al menos simbólicamente- la distancia con Galicia/España, a la luz de los posts analizados Facebook mitiga el aislamiento entre los peñistas distribuidos en todo el territorio argentino, reafirmando así la idea de comunidad.

Del sitio oficial de la peña "Lionel Scaloni" resulta que fue creada en 2013 por iniciativa de dos hinchas de Vélez Sárfield, el club argentino de Liniers, que simpatizaban también por el club gallego. Se trata, según puede leerse en el mismo sitio, de una de las pocas peñas en la Argentina dedicadas a un equipo de la Liga Española. La necesidad de su creación surge, de acuerdo a lo enunciado, por las dificultades inherentes a "capturar' algún bar o pizzería e implorar al dueño que cambie el canal del televisor". El relato continúa: "es importante ponerse en situación,.. a nuestro país solo llegaban transmisiones de partidos como el Barca o el Real. Hoy con internet y varias alternativas de tv prepaga se hace todo más [sic] fácil. Pero hace un 
par de años atrás, era una hazaña que pocos conseguirían" (http://www.deportivolacoruña.com.ar/historia.htm). El objetivo es juntarse a ver los partidos del "Depor" pero también el de "unir culturas y transmitir la cultura gallega en Argentina y el mundo" (http://www.deportivolacoruña.com.ar/).

Si bien no existe un punto fijo de encuentro, el Centro Galicia de Buenos Aires es, en palabras de los organizadores de la peña, su "sede preferida". Allí se realizó el primer encuentro, en la calle Bartolomé Mitré del barrio Once de septiembre de la Ciudad de Buenos Aires. "Es un lugar con mucha historia, el cual nos abrió siempre las puertas y ocupa un lugar muy importante en todos nuestros corazones", reconoce uno de los organizadores de la peña. Aunque la publicidad de la "xuntada" está incluida en la cartelera institucional del Centro Galicia y en la vidriera contigua de la Xunta de Galicia, es imposible llegar al encuentro de la peña sin ser guiado por alguien que concurra al mismo evento. El bar está ubicado en el tercer piso del edificio del Centro Galicia y cuando éste está cerrado hay que ingresar por el estacionamiento de al lado. Uno de los peñistas me dice que no sabe si la peña se va a seguir manteniendo como hasta ahora porque creció mucho y "no da" para hacer las "xuntadas" en un lugar "privadísimo" como este. "La solución podría ser una lista de invitados", asevera. Sin embargo, hoy la convocatoria es escasa. Acaso por la proximidad de las fiestas..., me explican. Uno de los organizadores se lamenta porque la logística de cada uno de los encuentros implica mucho trabajo.

Finalmente llegamos. El lugar de encuentro es amplio; las paredes son claras. Está limpio y ordenado. La barra del bar es de mármol; está recubierta en madera y el fondo es de espejo con una arcada, también de madera. Me recuerda la escenografía de un programa -Polémica en el bar- ya clásico en la televisión argentina... Sobre la barra hay un teléfono semi-público. Y un arbolito de Navidad. El bar se encuentra detrás de tres paneles de rejas corredizas. En la sala hay sillas plegables apiladas sobre las paredes que dan cuenta del uso del espacio por una gran concurrencia. Además, hay mesas y sillas de madera, como las de cualquier bar o restaurante de Buenos Aires. También hay un imponente perchero de madera con espejo. Más allá, tres heladeras exhibidoras de gaseosas vacías aparentemente fuera de uso.

Las mesas fueron unidas formando una línea recta orientada al televisor, que pende sobre un soporte en lo alto de una columna. Debajo del televisor hay una mesa, sobre la que se apoya una computadora portátil que está unida al televisor a través de un cable. Después de diversos intentos, uno de los organizadores logra finalmente conectar el televisor a internet. Aparece el partido en la pantalla. El Deportivo La Coruña enfrenta al Celta de Vigo en el Riazor. Los relatores son, a juzgar por los rasgos que presenta el relato, españoles. Me explican que cuando lo siguen a través de ESPN play la transmisión es directamente desde España. La

Question, Vol. 1, N. ${ }^{\circ}$ 63, julio-septiembre 2019. ISSN 1669-6581

Instituto de Investigaciones en Comunicación | Facultad de Periodismo y Comunicación Social | Universidad Nacional de La Plata La Plata | Buenos Aires | Argentina

Página 9 de 13 
calidad de la imagen es aceptable. No obstante, cada tanto permanece congelada. "-Poné roja directa... capaz no se corta”. -“No, es internet eso", acotan dos peñistas. De repente, solo se escucha el audio de un gol cuyo festejo llega en diferido... Les pregunto por qué no lo ven por CRTVG. Me responden que los únicos partidos que transmite la señal internacional del canal gallego son los regionales, "que no valen nada". Por cuestión de derechos, los de la Liga no los pasan...

Según la información suministrada por una funcionaria de CRTVG,

[o] 31 de decembro de 1996 empezouse a emitir conxuntamente en América con TV3 E ETB a través do canal denomidado Galeusca (satélite PanAmSat). Aos tres meses deixamos de emitir de forma conxunta e iniciamos as emisións de Galicia TV. Estas emisións a través de satélite estaban amparadas na modificación da lei do tecer canal realizada en 1995 (Funcionaria de CRTVG, correo electrónico, 7 de junio de 2017).

En la actualidad, las emisiones de Galicia TV América llegan a la Argentina a través del satélite Hispasat 1E, que las recibe en abierto. Además, la señal es distribuida a través de diez operadores de la televisión por cable, garantizando la cobertura en casi la totalidad del territorio argentino. Entre ellos se destaca Cablevisión por la cantidad de abonados que registra, estimada en un millón doscientos mil aproximadamente. "O noso obxectivo é ofrecer programación variada para todos os sectores da poboación", declara la funcionaria. Sin embargo, reconoce: "sólo tenemos derechos universales para los partidos de fúbol de $2^{\text {a }} \mathrm{B}$ y tercera división" (funcionaria de CRTVG, correo electrónico, 17 de agosto de 2018). Así pues, no basta que la televisión pública regional transmita la señal de manera abierta; el fútbol gallego transnacional debe pasar por el doble tamiz de los intereses comerciales en origen y en destino.

Hoy la audiencia está compuesta por trece personas, tres de las cuales somos mujeres. Una está acompañando a su novio; la otra llegó sola. La presencia minoritaria de las mujeres en la composición de la audiencia tal vez pueda ser explicada en términos de las pocas mujeres registradas entre el centenar de peñistas a lo largo y a lo ancho del país. Sin embargo, las cámaras en el estadio se detienen con frecuencia en rostros femeninos. Dicha escasez resulta aun más significativa si se tiene en cuenta que el club es uno de los pocos a nivel europeo que cuenta con un equipo femenino de fútbol. Salvo el mozo, las y los televidentes son jóvenes. A la peña está afiliada solo una familia que incluye al peñista más joven de tan solo dos meses de edad. Uno de los organizadores me explica que la mayoría de los socios de la peña son 
hinchas del "Depor" por herencia. Otro confiesa que, aunque no tiene ascendencia gallega, es hincha del Depor porque lo juega en la "play".

Se autodefinen como un grupo de amigos. Pero principalmente como argentinos. Curiosamente, uno de los organizadores lleva puesta la camiseta del "Depor" y el pantalón de River Plate. La identificación con la argentinidad se vuelve explícita asimismo en las elecciones gastronómicas que incluyen una picada, pizzas y empanadas (no gallegas). O bien lingüísticas: nadie se reconoce hablante de la lengua gallega. Todos los comentarios, incluso las "puteadas", típico modo de vivenciar este deporte, son en castellano. Con respecto a la preferencia por el relato en "español" o en castellano rioplatense, argumentan: "(acá) le ponen más energía. El español es más técnico que pasional. Son distantes. El ambiente cambia muchísimo. Acá se mimetiza entre relator y comentarista". Pero podría argumentarse que dicha "neutralidad" no sería más que una ilusión ya que los rasgos culturales, aunque atenuados, son facilmente identificables por las y los televidentes.

Con todo, las identificaciones al interior de la audiencia no parecen ser excluyentes. No sólo la peña contaba, hasta su retorno reciente a Galicia, con un gallego nativo, sino que hoy la audiencia de la peña incluye a dos hinchas del Celta de Vigo, el clásico rival del "Depor". Uno de los hinchas del Celta cuenta que un día se cansó del fútbol argentino y empezó a seguir al Celta porque su familia es originaria de Vigo. De hecho, al ser consultadas y consultados por los motivos por los que asisten a la peña, todos destacan "compartir. No todos los días te cruzas con hinchas de otro país (de un club) así de chico. Está bueno encontrarse. Por un equipo que juegan [sic] tan lejos...". También convoca el desempeño de futbolistas argentinos, como el poroto Lux, en el club gallego: "más de 70 argentinos jugaron en la Coruña. Mucha gente se acercó por la carrera de jugadores argentinos".

Parafraseando a Glick (2009; 2008), se hace evidente que es necesario estudiar la recepción del fútbol transnacional en relación al espacio antes que utilizar al grupo étnico como unidad de análisis. A tal fin, es preciso recuperar la noción de localidad de un modo relacional, posicionando migrantes y nativos en el mismo marco conceptual. Se trata de una propuesta potencialmente valiosa, sobre todo si se tiene en cuenta que la discusión académica sobre las audiencias de televisión transnacionales ha sido en buena medida informada por el nacionalismo metodológico, sin examinar adecuadamente ni la relación con lo local ni las dinámicas con grupos de personas no identificables como migrantes, si por ellos entendemos a quien concreta en primera persona la experiencia del desplazamiento.

Cierre y perspectivas

En base a los desarrollos anteriores es posible concluir este trabajo afirmando que la recepción transnacional del fútbol gallego en Buenos Aires no está exenta de conflictos. Dicha

Question, Vol. 1, N. ${ }^{\circ}$ 63, julio-septiembre 2019. ISSN 1669-6581

Instituto de Investigaciones en Comunicación | Facultad de Periodismo y Comunicación Social | Universidad Nacional de La Plata 
conflictividad se hace explícita, por ejemplo, en referencia a la posibilidad efectiva de incidir, al menos en parte, sobre la oferta televisiva tanto en origen como en destino. En este mismo sentido, la identificación con la Argentina y su lengua parece operar como homogeneizador al interior del grupo pero también marcar acaso ciertos límites a una imaginación futbolística, aunque no solo, centrada en lo territorial.

A nivel teórico, podría argumentarse que el análisis del caso de la peña "Lionel Scaloni" del Deportivo La Coruña señala la deseabilidad, ya advertida en otros ámbitos dentro de los estudios transnacionales, de relativizar la pertinencia del grupo étnico como unidad de análisis para estudiar las audiencias de televisión transnacionales y recuperar, en cambio, una noción relacional de la localidad. Se trata de un programa de investigación que apunta a desterrar el nacionalismo metodológico no solo de los estudios migratorios sino también de la investigación sobre las audiencias televisivas.

\section{Bibliografía}

Aksoy, A. y Robins, K. (2005). Whoever looks always finds: transnational viewing and knowledge-experience. En Chalaby, J. (ed.). Transnational Television Worldwide. Londres: Tauris.

Aksoy, A. y Robins, K. (2003). Banal transnationalism. En Karim, K. (ed.). The Media of Diaspora. Londres: Routledge.

Aksoy, A. y Robins, K. (2000). Thinking across spaces. European Journal of Cultural Studies, 3(3), pp. 343-365.

Barra, L.; Tarantino, M. y Tosoni, S. (2011). Etnografia virtuale e convergenza: spazi, tempi, discorsi e pratiche della TV sul web. En Tosoni, S. (comp.). Nuovi media e ricerca empirica. I percorsi metodologici degli internet Studies. Milán: Vita e Pensiero.

Glick, N. (2008). A global perspective on migration and development. Social Analysis, 53(3), pp. 14-37.

Glick, N. (2009). Nuevas y viejas cuestiones sobre localidad: teorizar la migración trasnacional en un mundo neoliberal. En Solé, C.; Parella, S. y L. Cavalcanti (coord.). Nuevos retos del transnacionalismo en el estudio de las migraciones. Madrid: Ministerio de Trabajo e Inmigración.

Guber, R. (2011). La etnografía. Método, campo y reflexividad. Buenos Aires: Siglo veintiuno.

Guber, R. (2004). El salvaje metropolitano. Reconstrucción del conocimiento social en el trabajo de campo. Buenos Aires: Paidós.

Question, Vol. 1, N. ${ }^{\circ}$ 63, julio-septiembre 2019. ISSN 1669-6581

Instituto de Investigaciones en Comunicación | Facultad de Periodismo y Comunicación Social | Universidad Nacional de La Plata 
Grimson, A.; Masotta, C. y Varela, M. (1999). Un electrodoméstico en la ciudad. Hacia una conceptualización del lugar de la televisión en el espacio público. En Grimson A. y Varela, M. (comp.). Audiencias, cultura y poder. Estudios sobre televisión. Buenos Aires: Eudeba.

Lozano, J. y Frankenberg, L. (2008). Enfoques teóricos y estrategias metodológicas en la investigación empírica de audiencias televisivas en América Latina: 1992-2007. Comunicación y Sociedad, 10, pp. 81-110.

Márquez, I. (2014). Ética de la investigación etnográfica en los cibermundos. Anthropologica, 33, pp. 111-135.

Portes, A.; Escobar, C. y Arana, R. (2009). ¿Lealtades divididas o convergentes? Informe sobre la incorporación política de inmigrantes latinoamericanos en los Estados Unidos. En Solé, C.; Parella, S. y L. Cavalcanti (coord.). Nuevos retos del transnacionalismo en el estudio de las migraciones. Madrid: Ministerio de Trabajo e Inmigración.

Saintout, F. y Ferrante, N. (2006). Los estudios de recepción en Argentina hoy: rupturas, continuidades y nuevos objetos. En ¿Y la recepción? Balance crítico de los estudios sobre el público. Buenos Aires, La Crujía.

Uribe Alvarado, A. (2005). México imaginado. Estudios sobre las Culturas Contemporáneas, XI, pp. 9-33.

Uribe Alvarado, A. (2004a). Receptores nómadas: confluencias entre recepción televisiva y migración trasnacional. Intexto, 2, pp. 1-18.

Uribe Alvarado, A. (2004b). Una perspectiva cualitativa en un estudio de recepción televisiva. Estudios sobre las Culturas Contemporáneas, X(20), pp. 141-168.

Villena Fiengo, S. (2003). Gol-balización, identidades nacionales y fútbol. En Alabarces, P. (comp.). Futbologías. Fútbol, identidad y violencia en América latina. Buenos Aires: CLACSO. 